Repository of the Max Delbrück Center for Molecular Medicine (MDC) Berlin (Germany)

Forced Expression of LIM Homeodomain Transcription Factor $1 \mathrm{~b}$ Enhances Differentiation of Mouse Embryonic Stem Cells into Serotonergic Neurons

Virginie Dolmazon, Natalia Alenina, Suzy Markossian, Jimmy Mancip, Yvonne van de Vrede, Emeline Fontaine, Colette Dehay, Henry Kennedy, Michael Bader, Pierre Savatier, and Agnieszka Bernat

This is a copy of an article published in the "Stem Cells and Development" (C) 2011 copyright Mary Ann Liebert, Inc.; "Stem Cells and Development" is available online at: http://online.liebertpub.com. 


\title{
Forced Expression of LIM Homeodomain Transcription Factor 1b Enhances Differentiation of Mouse Embryonic Stem Cells into Serotonergic Neurons
}

\author{
Virginie Dolmazon, ${ }^{1-3}$ Natalia Alenina, ${ }^{4}$ Suzy Markossian, ${ }^{1-3}$ Jimmy Mancip, ${ }^{1-3}$ \\ Yvonne van de Vrede, ${ }^{1-3}$ Emeline Fontaine, ${ }^{1-3}$ Colette Dehay, ${ }^{1-3}$ Henry Kennedy, ${ }^{1-3}$ \\ Michael Bader, ${ }^{4}$ Pierre Savatier, ${ }^{1-3}$ and Agnieszka Bernat ${ }^{1-3}$
}

The LIM homeodomain transcription factor $1 b(\operatorname{Lmx} 1 b)$ is a key factor in the specification of the serotonergic neurotransmitter phenotype. Here, we explored the capacity of Lmx1b to direct differentiation of mouse embryonic stem (mES) cells into serotonergic neurons. mES cells stably expressing human Lmx1b were generated by lentiviral vector infection. Clones expressing Lmx1b at a low level showed increased neurogenesis and elevated production of neurons expressing serotonin, serotonin transporter, tryptophan hydroxylase 2, and transcription factor Pet1, the landmarks of serotonergic differentiation. To explore the role of Lmx1b in the specification of the serotonin neurotransmission phenotype further, a conditional system making use of a floxed inducible vector targeted into the ROSA26 locus and a hormone-dependent Cre recombinase was engineered. This novel strategy was tested with the reporter gene encoding human placental alkaline phosphatase, and demonstrated its capacity to drive transgene expression in nestin ${ }^{+}$neural progenitors (NPs) and in Tuj $1^{+}$neurons. When it was applied to inducible expression of human Lmx1b, it resulted in elevated expression of serotonergic markers. Treatment of neural precursors with the floor plate signal Sonic hedgehog further enhanced differentiation of Lmx1boverexpressing NPs into neurons expressing 5-HT, serotonin transporter, tryptophan hydroxylase 2, and Pet1, when compared with Lmx1b-nonexpressing progenitors. Together, our results demonstrate the capacity of Lmx1b to specify a serotonin neurotransmitter phenotype when overexpressed in mES cell-derived NPs.

\section{Introduction}

E MBRYONIC STEM (ES) CELLS have the capacity to differentiate into a large variety of cells types in vitro, owing to their high self-renewal capacity and intrinsic pluripotentiality [1]. ES cells can be used to dissect the molecular mechanisms underlying in vitro differentiation into specialized cell types, such as serotonergic neurons. Several protocols to coax differentiation of mouse, rhesus, and human ES (hES) cells into neural progenitors (NPs) and then to direct differentiation of those progenitors into serotonergic neurons have been described [2-7]. These protocols make use of growth factors and cytokines known to regulate serotonergic differentiation in the mouse central nervous system. Implicit to this experimental paradigm, the developmental program employed by ES cells to differentiate into serotonergic neurons in vitro, largely, if not fully, recapitulates the developmental program executed during neurogenesis in the developing embryo.
Serotonergic (5-HT) neurons reveal a close ontogenetic relationship to midbrain dopaminergic (DA) neurons as both neuronal subtypes derived from ventral neuroepithelial progenitors located on either side of the midbrain-hindbrain boundary, starting at embryonic day 10.5 in the mouse [8-10]. According to the prevailing model, the development of both 5-HT depends critically on sonic hedgehog (Shh) synthesized by the floor plate, fibroblast growth factor 8 (FGF8) generated by the midbrain-hindbrain organizer, and FGF4 produced by the primitive streak $[11,12]$. NPs located more rostrally, thus away from the FGF4 signal, differentiate into DA neurons.

Several transcription factors are involved in serotonergic differentiation. Mash1 and Nkx2.2 expressed in NPs of the hindbrain activate the transcription factors Gata2, Gata3, LIM homeodomain transcription factor $1 b(\operatorname{Lm} \times 1 b)$, and Pet1 [13], which together define the serotonergic cell type by activating marker genes such as for tryptophan hydroxylase 2 (TPH2), aromatic amino acid decarboxylase, the serotonin

\footnotetext{
${ }^{1}$ INSERM U846, Bron, France.

${ }^{2}$ Stem Cell and Brain Institute, Bron, France.

${ }^{3}$ Université de Lyon, Lyon, France.

${ }^{4}$ Max Delbrück Center for Molecular Medicine, Berlin, Germany.
} 
transporter (SERT), and the vesicular monoamine transporter 2 [14]. Both Gata2- and Gata3-deficient mice exhibit partial loss of serotonergic neurons $[13,15]$. In mice lacking Pet1, 70\% of serotonergic progenitors fail to differentiate, whereas in the remaining Pet1-deficient neurons diminished expression of TPH and SERT was observed [16]. Lmx1b is crucially involved in the formation of the entire serotonin system in the hindbrain, because its deletion in mice leads to the absence of 5-HT neurons in the brain [17-19]. It is expressed in developing 5-HT neurons together with Pet1 starting around E11 in the rostral cluster of serotonergic differentiation and 1 day after in the caudal one, consistent with the delayed appearance of serotonergic cells in the latter region [18]. Lmx1b ablation does not affect expression of Nkx2.2, Gata3, and Shh, putting these factors upstream of Lmx1b [17,18]. Together with Nkx2.2, GATA3, and Pet1, Lmx1b can induce ectopically the development of serotonergic neurons in the chick neural tube, a function that Nkx2.2 and Pet1 cannot support on their own $[18,20]$. Lmx1b is also involved in the maintenance of the DA neurotransmitter phenotype in collaboration with the orphan nuclear receptor Nurr1 [21]. Therefore, Lmx1b plays a central role in the differentiation of 5-HT neurons, and an ancillary role in the differentiation of midbrain DA neurons.

Differentiation of mouse ES (mES) cells into serotonergic neurons is highly efficient. In a pioneer study, sequential exposure of mES cell-derived nestin ${ }^{+}$NPs to FGF4 and then to FGF8 and Shh led to a 2.5-fold increase in the number of serotonergic neurons resulting in $\sim 25 \%$ of the neurons being 5-HT positive [22]. Using stromal cell cultures to induce differentiation of mES cells and adding the same combination of factors, Barberi et al. were able to define conditions in which the mouse ES cells were differentiated into 60\% 5-HT expressing neurons [3]. Similar results were obtained with hES cells. Under nonoptimized differentiation conditions, $<1 \%$ of the hES cell-derived neurons obtained are serotonin positive $[23,24]$. Addition of factors that included Shh, FGF4, FGF8, glial-derived neurotrophic factor, and brain-derived neurotrophic factor increased the number of 5-HT expressing cells to $25 \%$ of the $\beta$-III-tubulin-positive cell population. In a recent study, $40 \%$ of NPs could be converted to serotonergic neurons expressing serotonin, Tph2, and the transcription factors Mash1, Pet1, and Lmx1b [6].

Herein, we asked if overexpression of Lmx1b expression is sufficient to drive differentiation of mES cell-derived NPs to the serotonergic neuron pathway. We developed 2 experimental approaches, the first one based on lentiviral vectorbased stable expression and the second one on conditional expression induced by $4^{\prime}$ hydroxytamoxifen $\left(4^{\prime} \mathrm{OHT}\right)$ in NPs. In both experimental systems, Lmx1b was found to promote serotonergic differentiation, either alone or in cooperation with dorsoventralizing factors.

\section{Materials and Methods}

\section{Plasmid construction}

To engineer $p R 4 S A-E F S-C r e E R^{T 2}-W$, the $C r e-E R^{T 2}$ coding sequence from $p C r e-E R^{\mathrm{T} 2}$ [25] was subcloned between the EcoRV and Bam HI sites of plasmid $p R 4 S A-E F S-G F P-W$ [26].

To engineer $p 2 K 7-H A h L m x 1 b$, the human $L m x 1 b$ cDNA from $p c D N A 3.1 h L m x 1 b$ (a kind gift from $S$. Dreyer) was first $\mathrm{HA}$ tagged at its $\mathrm{N}$-terminus by polymerase chain reaction
(PCR) amplification. It was subsequently subcloned between $B a m \mathrm{HI}$ and EcoRV sites in plasmid $p G A E-C A G-e G F P-W P R E$ [27]. In a second step, the CAG promoter (CMV early enhancer/chicken $\beta$-actin) from $p G A E-C A G$-eGFP-WPRE was cloned into $p D O N R P 4-P 1 R$ (Invitrogen), and the HAhLmx1b cDNA from $p G A E-C A G-H A h L m x 1 b-W P R E$ was cloned into pDONR221 (Invitrogen), both using Gateway BP clonase enzyme mix (Invitrogen). The resulting 2 entry vectors were then recombined into 2 K7neo lentivector (kind gift of D. Suter) using Gateway LR plus clonase enzyme mix (Invitrogen) [28].

To engineer $p I G T E 2-R 26-h P L A P$, a 48-mer oligonucleotide containing a $\mathrm{PaCI}$ site $\left(5^{\prime}\right.$-attttaattaagaagttcctattctctag aaagtataggaacttcgat- $3^{\prime}$ ) and a 54-mer oligonucleotide containing an AscI site (5'-ctagagctagcgaagttcctattcttcaaatagtat aggaactt $\operatorname{cggcgcgcca}-3^{\prime}$ ) were first subcloned into the SspI and AscI sites of plasmid pIGTE2-hAP [29], respectively. The resulting plasmid was digested with $P a c I$ and $A s c \mathrm{I}$, and the $3.8 \mathrm{~kb}$ fragment was subcloned between $P a c \mathrm{I}$ and $A s c \mathrm{I}$ in $p R o s a 26 P A$ [30] to generate $p I G T E 2-R 26-h P L A P$. To engineer pIGTE2-R26-hLmx1b, a $1.2 \mathrm{~kb}$ NheI/XbaI fragment encompassing human $L m x 1 b$ cDNA was prepared from $p c D N A 3.1 h L m x 1 b$ (a kind gift from S. Dreyer), and subcloned in $p C M V$-Ires- $p A$ to generate $p C M V h L m x 1 b$. The $p C M V h L m x 1 b$ plasmid was next digested with NheI, and the resulting $2.9-\mathrm{kb}$ insert was subcloned between both NheI sites into $p I G T E 2$ to generate $p I G T E 2-h L m x 1 b . P a c I$ and AscI sites were added as described above for pIGTE2-hAP, and the resulting $P a c \mathrm{I} / A s c \mathrm{I}$ fragment was subcloned between $P a c I$ and $A s c I$ in $p R o s a 26 P A$ to generate pIGTE2-R26$h L m x 1 b$.

\section{mES cell culture and electroporation}

mES cells (CGR8) were maintained on $0.1 \%$ gelatinized (Sigma) tissue culture dishes in Glasgow's modified Eagle's medium supplemented with $10 \%$ fetal calf serum (Biowest), $1,000 \mathrm{U} / \mathrm{mL}$ of leukemia inhibitory factor (LIF), $1 \mathrm{mM}$ sodium pyruvate, $2 \mathrm{mM}$ L-glutamine, $100 \mathrm{U} / \mathrm{mL}$ penicillin$100 \mu \mathrm{g} / \mathrm{mL}$ streptomycin, and $100 \mu \mathrm{M} \beta$-mercaptoethanol (all from Invitrogen). About $5 \times 10^{6}$ CGR8 cells were electroporated at $0.26 \mathrm{kV}$ and $960 \mu \mathrm{F}$ with $40 \mu \mathrm{g}$ of pIGTE2-R26$h P L A P$ or $p I G T E 2-R 26-h L m x 1 b$ plasmid linearized with SwaI. Stably transfected cells were selected with $80 \mu \mathrm{g} / \mathrm{mL}$ hygromycine B (Roche Applied Science) for 8 days. Drug-resistant colonies were expanded before analysis and frozen.

\section{Neuronal differentiation}

Neural induction and neuronal differentiation were performed by means of coculture of mES cells with the MS5 stromal cell line as previously described [3]. In brief, $\mathrm{mES}$ cells were seeded at a density of $10-50$ cells $/ \mathrm{cm}^{2}$ on the layer of mitomycin-inactivated MS5 cells, and maintained in knockout Dulbecco's Modified Eagle's Medium (DMEM) supplemented with $15 \%$ (vol./vol.) knockout serum replacement, $2 \mathrm{mM}$ L-glutamine, and $10 \mu \mathrm{M} \beta$-mercaptoethanol (all from Invitrogen), for 8 days to allow neural induction. Neuroepithelial colonies were harvested with a fire-pulled Pasteur pipette, dissociated by gentle trypsinization, and replated on Matrigel (BD Biosciences)-coated dishes in Neurobasal medium without phenol red, supplemented with $200 \mathrm{mM}$ glutamine, $5 \mu \mathrm{g} / \mathrm{mL}$ bovine fibronectin, $\mathrm{N} 2$ and B27 
supplement (all from Invitrogen), and $20 \mathrm{ng} / \mathrm{mL}$ FGF2 (AbCys). FGF4 (100 ng/mL), FGF8 (100 ng/mL), and SHH ( $200 \mathrm{ng} / \mathrm{mL}$ ) (R\&D Systems) were added to the culture medium at times indicated. To induce neuronal differentiation, FGF2 was withdrawn from the medium at day 11-12, and replaced with $20 \mathrm{ng} / \mathrm{mL}$ brain-derived neurotrophic factor (R\&D Systems), $200 \mu \mathrm{M}$ ascorbic acid (Sigma), and $20 \mathrm{ng} / \mathrm{mL}$ neurotrophin 3 (R\&D Systems). Final differentiation was allowed for 5-6 days. 4'OHT (Calbiochem) was added to the culture medium for the time and concentration indicated.

Neural differentiation was also induced by the formation of embryoid bodies (EBs) as previously described [5,31,32]. In brief, $6 \times 10^{6}$ ES cells were cultured in suspension in $10 \mathrm{~mL}$ of the medium (Glasgow's modified Eagle's medium supplemented with $10 \%$ vol./vol. knockout serum replacement, $2 \mathrm{mM}$ L-glutamine, $1 \mathrm{mM}$ sodium pyruvate, and $1 \times$ non essential amino acids (NEAA); all from Invitrogen) in a $10-\mathrm{cm}$ dish. After 8 days, EBs were dissociated and replated at a density of $2.5 \times 10^{4}$ cells $/ \mathrm{cm}^{2}$ on poly-D-lysine/laminin (Sigma) in the N2B27 medium (Invitrogen). After replating, neural precursor cells were enriched for 2 days by the addition of $10 \mathrm{ng} / \mathrm{mL}$ FGF2 (R\&D Systems). Withdrawal of FGF2 in the N2B27 medium resulted in production of postmitotic neurons (from day 11 to 18 ).

\section{Production of lentiviral vectors and infection}

The method for simian immunodeficiency virus (SIV)based vector production in $293 \mathrm{~T}$ cells is fully described elsewhere [26,33]. In brief, 2937 cells were transfected by the calcium phosphate method with a mixture of DNA containing $p G R e v$ plasmid encoding the vesicular stomatitis virus glycoprotein envelope, $p S I V 3+$ plasmid encoding the gag, pol, tat, and rev proteins, and pR4SA-EFS-CreER $R^{T 2}-W$. The next day, cells were refed with the fresh medium and further cultured for $48 \mathrm{~h}$. The supernatant was then collected, cleared by centrifugation (3,000 rpm and $15 \mathrm{~min})$, and passed through a $0.8-\mu \mathrm{M}$ filter to remove cell and debris. For infection, $10^{4}$ freshly trypsinized mES cells were resuspended into $1 \mathrm{~mL}$ of $293 \mathrm{~T}$ cell supernatant producing the desired virus in the presence of $8 \mu \mathrm{g} / \mathrm{mL}$ sequabrene (Sigma), plated on a 2-cmdiameter dish, and cultured for $48 \mathrm{~h}$ before cloning by limiting dilution. The production of lentiviral particles from plasmid p2K7neo-HAhLmx1b was performed as described $[28,34]$.

\section{DNA and RNA extraction, Southern blot, and real-time $P C R$}

For genomic DNA extraction, cells were lysed in $10 \mathrm{mM}$ Tris- $\mathrm{HCl}(\mathrm{pH}$ ), $1 \mathrm{mM}$ ethylenediaminetetraacetic acid ( $\mathrm{pH}$ 8), $100 \mathrm{mM} \mathrm{NaCl}$, and $0.5 \%$ sodium dodecyl sulfate. The resulting lysate was treated with $0.2 \mathrm{mg} / \mathrm{mL}$ RNase for $1 \mathrm{~h}$ at $37^{\circ} \mathrm{C}$, followed by proteinase $\mathrm{K}$ treatment $(0.2 \mathrm{mg} / \mathrm{mL}$, $55^{\circ} \mathrm{C}$, overnight). DNA was separated from proteins by phenol-chloroform extraction, precipitated with isopropanol, and resuspended in $1 \mathrm{mM}$ Tris- $\mathrm{HCl}$ and $0.1 \mathrm{mM}$ ethylenediaminetetraacetic acid ( $\mathrm{pH} 8)$. Ten micrograms of EcoRV-digested genomic DNA was separated on a $0.8 \%$ agarose gel, transferred to a nylon membrane $\left(\right.$ Hybond- $\mathrm{N}^{+}$; Amersham), and hybridized with ${ }^{32} \mathrm{P}$-labeled (Ready-to-Go Labeling Kit; Amersham) probe. RNA was extracted using
RNAeasy kit (Qiagen) with on-column DNAse (Qiagen) digestion, and reverse transcription carried out with MuMLVRT (Promega) according to the manufacturer's recommendations. Quantitative PCR was performed using the LightCycler $^{\mathrm{TM}} 1.5$ system and the LightCycler Fast Start DNA Master SYBR Green I kit (Roche Applied Science) according to the manufacturer's instructions. Reactions were carried out in a total volume of $10 \mu \mathrm{L}$, comprising $0.4 \mu \mathrm{M}$ of each primer, $0.75 \mu \mathrm{L}$ SYBR Green, $2.5 \mu \mathrm{L}$ of diluted cDNA, and $2-4 \mathrm{mM} \mathrm{MgCl} 2$ according to primers. Amplification and online monitoring was performed using the LightCycler 1.5 system. After 40 amplification cycles, melt-curve analyses were performed to verify that only the desired PCR product had been amplified. PCR efficiency of both the target and reference genes was calculated from the derived slopes of standard curves by LightCycler software (Roche Molecular Biochemicals; LightCycler Software, version 3.0). These PCR efficiency values were used to calculate the relative quantification values for calibrator-normalized target gene expression by LightCycler relative quantification software (version 1.0). All normalizations were carried out with $\beta$-actin. Semiquantitative PCR was performed using Euroblue Taq polymerase according to supplier (Eurobio) instructions. Sequences of primers are given in Supplementary Table S1 (available online at www .liebertonline.com/scd).

\section{Histochemical detection and immunolabeling}

Histochemical analysis for hAP expression in cultured cells and quantification of hAP activity in protein lysates were carried out as described previously [29]. For immunolabeling, cells were washed in phosphate-buffered saline (PBS) and fixed in $4 \%$ paraformaldehyde in PBS at room temperature for $30 \mathrm{~min}$. After the rinse with PBS, cells were permeabilized in $0.2 \%$ Triton X-100 in PBS for $15 \mathrm{~min}$. Nonspecific binding was blocked with nonimmune normal goat serum (Zymed) for $30 \mathrm{~min}$ at room temperature. Primary antibodies were applied in $1 \%$ normal goat serum (Invitrogen) in PBS. The following primary antibodies were used: human placental alkaline phosphatase (hPLAP; Sigma), $\beta$-III-tubulin (Chemicon and Covance), PSA-NCAM (Chemicon), and 5-HT (Sigma). After incubation at $37^{\circ} \mathrm{C}$ for $1 \mathrm{~h}$, followed by several rinses in PBS, appropriate fluorochromeconjugated secondary antibodies were added (Molecular Probes). The cells were incubated at $37^{\circ} \mathrm{C}$ for $30 \mathrm{~min}$ and, after extensive washes in PBS, mounted on glass microscope slides using Vectashield HARD mounting medium (Vector Labs, Inc.) containing DAPI for DNA counterstaining.

\section{Enzyme-linked immunosorbent assay}

To evaluate the 5-HT level in postmitotic neuronal culture, cells were lysed in PBS containing $0.1 \%$ ascorbic acid (Sigma) by repeated freezing $\left(-80^{\circ} \mathrm{C}\right)$ and thawing. The extracts were sonicated and separated from debris by centrifugation ( $30 \mathrm{~min}$ $14,000 \mathrm{rpm})$. The protein concentration was estimated using Coomassie blue staining. Enzymatic immunoassay for 5-HT was performed with nano-detection kit Serotonin EIA BA 10-0900 (Labor Diagnostika Nord) following manufacturer's instructions. Serotonin concentration measured with the EIA kit was normalized to total protein content. 
A

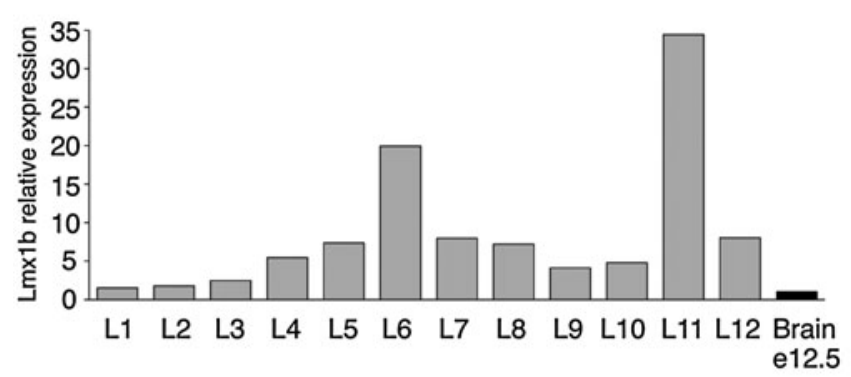

B

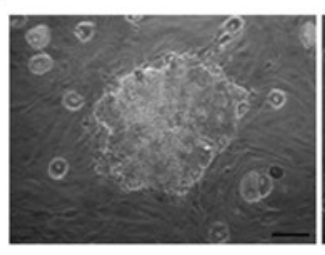

Control

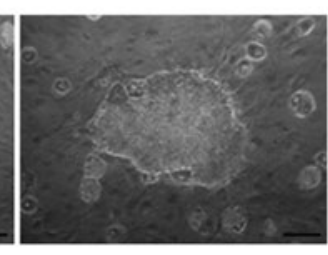

L1

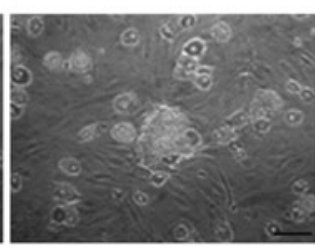

L11
E
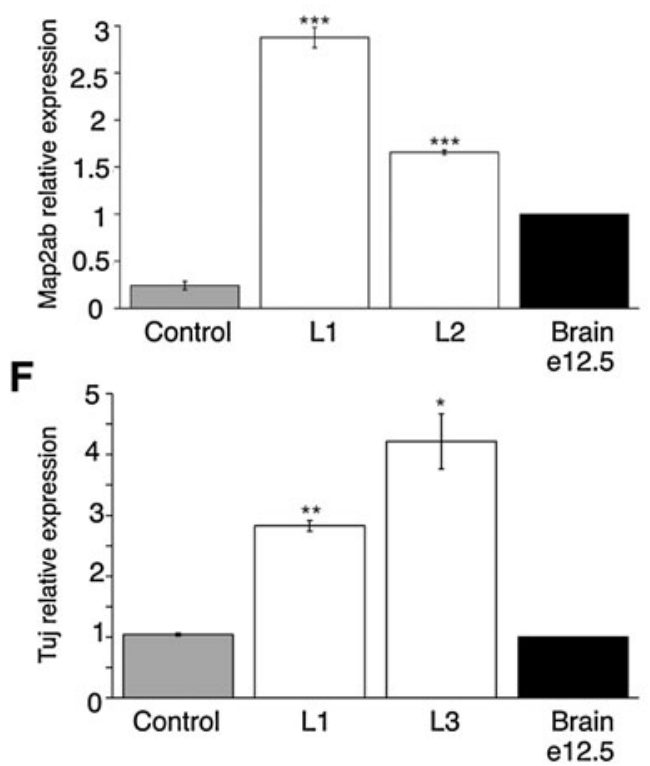

C

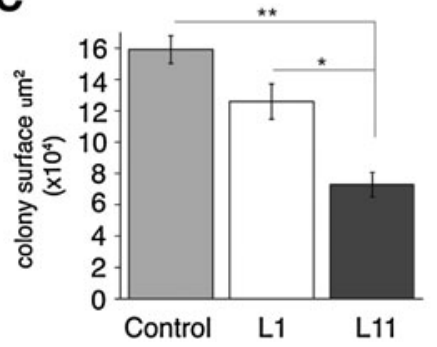

D

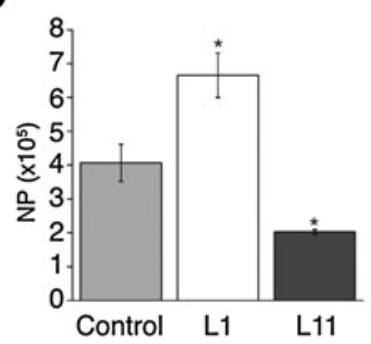

G

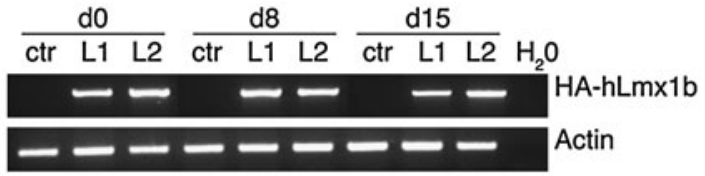

FIG. 1. Neuronal differentiation of mouse embryonic stem (mES) cells overexpressing human LIM homeodomain transcription factor $1 \mathrm{~b}(h L m x 1 b)$. (A) Real-time polymerase chain reaction (PCR) analysis of $h L m x 1 b$ mRNA level in mES cell clones (L1-L12) infected with $p 2$ K7-HAhLmx1b. (B) Neuroepithelial colonies at day 8 of differentiation formed by clones L1, L11, and control cells, MS5 protocol. Scale bar: $100 \mu \mathrm{m}$. (C) Surface of neuroepithelial colonies at day 8 of differentiation in clones L1 and L11, and in control cells (MS5 protocol). (D) Counting of neural progenitors (NPs) at day 12 of differentiation obtained with clones L1 and L11, and control cells (MS5 protocol). (E) Real-time PCR analysis of Map2ab expression levels at day 15 of differentiation with clones L1 and L2, and with control cells (MS5 protocol) after normalization with p-actin. (F) Real-time PCR analysis of Tuj1 expression levels at day 17 of differentiation in clones L1 and L3, and with control cells (embryoid body protocol). (G) Semiquantitative reverse transcriptase (RT)-PCR analysis of $H A-h L m x 1 b$ expression in clones L1 and L2, and in control cells, at day 0 (mES cells), day 8 (neuroepithelial colonies), and day 15 (postmitotic neurons) (MS5 protocol). (C-F) Histograms represent means and standard errors calculated in 3 replicates. Statistical significance was determined with the unpaired two-sided $t$-test $\left({ }^{*} P<0.05 ;{ }^{* *} P<0.01 ;{ }^{* * *} P<0.001\right)$. (A, E, F) Expression levels are normalized to the level measured in e12.5 total brain.

\section{Results}

\section{Neuronal differentiation of mES cells overexpressing $L m x 1 b$}

CGR8 mES cells were infected with $p 2 K 7-H A h L m x 1 b$, a lentiviral vector expressing human $\operatorname{Lm} x 1 b$ cDNA driven by the ubiquitous CAG promoter. Clones expressing $h L m x 1 b$ at low (L1, L2, L3, L4, L9, and L10), intermediate (L5, L6, L7, L8, and L12), and high (L11) levels were isolated (Fig. 1A). They were cultured onto MS5 stromal cells for 8 days to form neuroepithelial colonies, which were subsequently dissociated and replated on Matrigel-coated dishes in the presence of FGF2 to amplify a morphologically homogenous population of NPs, which is uniformly immunoreactive for NP-specific antigens such as nestin and PSA-NCAM [3] (hereafter called
MS5 protocol). NPs were induced to differentiate into Tuj1 ${ }^{+}$ neurons by withdrawal of FGF2 for 4-6 days (data not shown). We observed that $h L m x 1 b$ expression dramatically influenced both the yield of neuroepithelial colonies at day 8 and the yield of NPs after colony dissociation and replating at day 12. More specifically, clone L11 (high expressor) produced significantly smaller neuroepithelial colonies in comparison either with control mES cells (56\% reduction in size) or with low expressor L1 (43\% reduction) (Fig. 1B, C). Of note, the number of neuroepithelial colonies did not vary significantly between clones, indicating that $h L m x 1 b$ expression did not interfere with clonigenicity and survival of dissociated $\mathrm{mES}$ cells in these culture conditions (data not shown). We thus hypothesized that $h L m \times 1 b$ overexpression altered proliferation and/or survival of transient amplifying NPs. This hypothesis was confirmed after counting NPs upon dissociation of neu- 


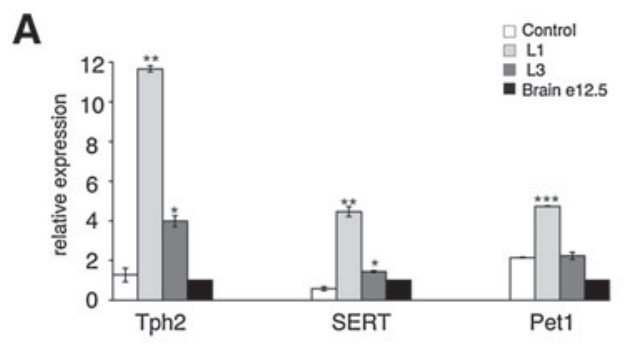

B

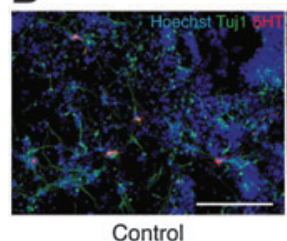

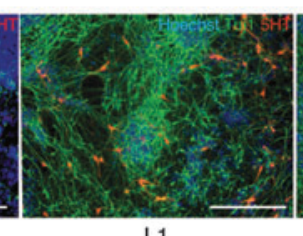

L1

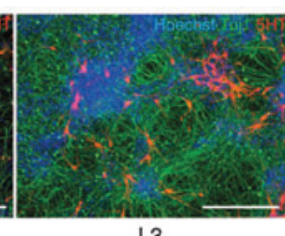

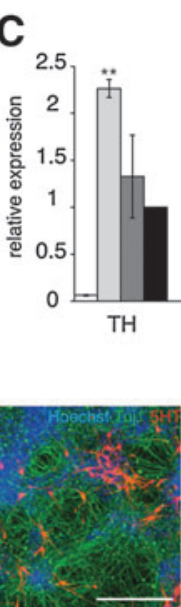

L3

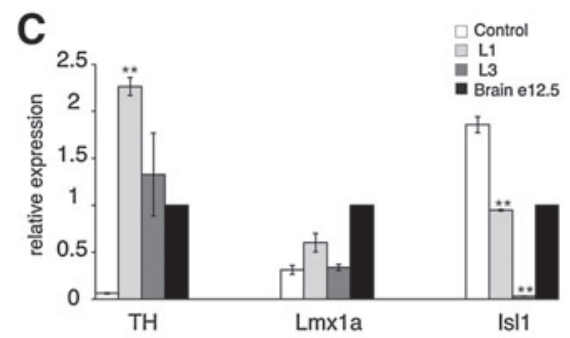

D

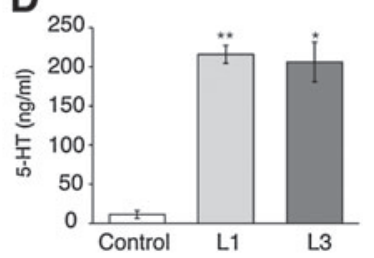

FIG. 2. Serotonergic and dopaminergic differentiation of mES cells overexpressing $h L m x 1 b$ (embryoid body protocol). Realtime PCR analysis of tryptophan hydroxylase 2 (Tph2), serotonin transporter (SERT) and Petl (A), tyrosine hydroxylase (TH), Lmx1a, and Isl1 (C), mRNA levels in clones L1 and L3, and in control cells, at day 17 of differentiation. Expression levels are normalized to Tuj1 and then to the level measured in e12.5 total brain. (B) Double immunofluorescence analysis of Tuj1 (green)- and 5-HT (red)-positive neurons, performed at differentiation day 15 of clones L1 and L3, and control cells. Nuclei are labeled with DAPI. Scale bar: $250 \mu \mathrm{m}$. (D) Quantification of 5-HT in cell extracts of neuron cultures at day 17 of differentiation by serotonin enzyme-linked immunosorbent assay. (A, C, D) ${ }^{*} P<0.05 ;{ }^{* *} P<0.01 ;{ }^{* * *} P<0.001$.

A

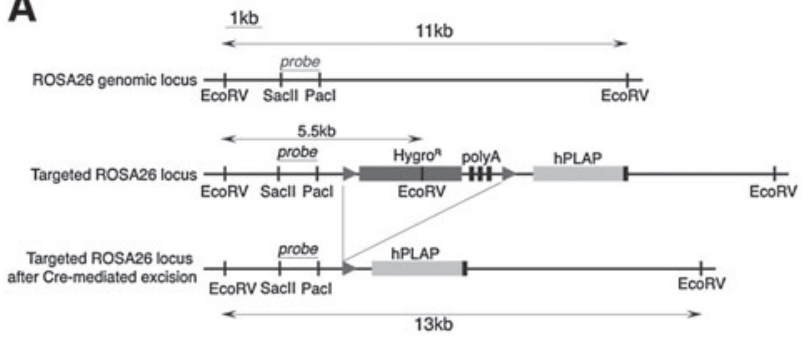

B

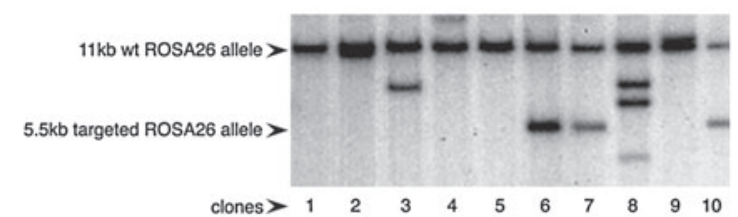

C

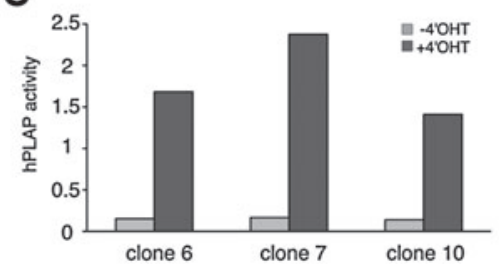

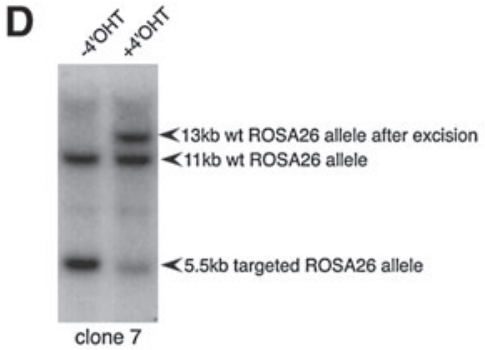

E
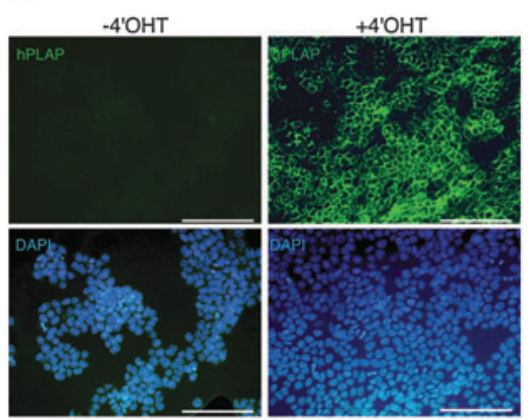

FIG. 3. Generation of an inducible expression vector and ES cell line for conditional gene expression. (A) Schematic representation of the ROSA26 locus after targeted integration of $p I G T E 2-R 26-h P L A P$ plasmid before and after Cre-mediated excision of the hygro-polyA cassette. The position of the SacII-PacI probe used for Southern blot analysis is indicated. Hygro ${ }^{R}$, gene conferring resistance to hygromycin B; PolyA, transcription termination and polyadenylation signals. (B) Southern blot analysis of the ROSA26 locus after digestion with EcoRV and hybridization with a radioactive probe. (C) Human placental alkaline phosphatase (hPLAP) activity measured in 3 independent undifferentiated WTC15-R26-hPLAP clones before and after treatment with $100 \mathrm{nM} 4^{\prime}$ hydroxytamoxifen $\left(4^{\prime} \mathrm{OHT}\right)$ for $48 \mathrm{~h}$. (D) Southern blot analysis of the ROSA26 locus in WTC15R26-hPLAP-7 clone after digestion with EcoRV, before and after treatment with 4'OHT (100 nM, 48 h). (E) Immunofluorescence analysis of $h P L A P$ expression in NPs and postmitotic neurons before and after treatment with $4^{\prime} \mathrm{OHT}(100 \mathrm{nM}$, $48 \mathrm{~h}$ ). Low panels show DAPI staining of DNA. Scale bar: $100 \mu \mathrm{m}$. 
roepithelial colonies at day 8 , and subsequent culture for 4 days. Clone L11 (high expressor) exhibited a 50\% reduction in the yield of nestin ${ }^{+}$NPs at day 12 compared with wild-type ES cells (Fig. 1D). Moreover, after withdrawal of FGF2, most L11-derived NPs failed to differentiate into mature neurons and degenerated (data not shown). In sharp contrast, clone L1 (low expressor) produced a $63 \%$ increase in nestin ${ }^{+} \mathrm{NP}$ number at day 12 (Fig. 1D) and, at day 15 (ie, 3 days after mitogen withdrawal), a 12-fold increase in pan-neuronal marker Map2ab expression. Comparable results were obtained with the low expressor L2 (Fig. 1E).

Similar data were obtained after neuronal differentiation induced by formation of EBs for 8 days, followed by replating for 2 days in the presence of FGF2, and subsequent mitogen withdrawal for 7 days (EB protocol). Compared with control cells, the low expressors L1 and L3 showed a 2.7- and 4-fold increase in pan-neuronal marker Tuj1 expression, respectively (Fig. 1F). Of note, $h L m x 1 b$ was expressed at constant levels throughout differentiation (Fig. 1G). Together, these results suggest that moderate overexpression of Lmx1b significantly increases the yield of neural/neuronal differentiation of mES cells.

\section{ES cells overexpressing $L m \times 1 b$ show preferential differentiation toward serotonergic lineage in vitro}

We next wanted to determine if Lmx1b overexpression influences differentiation of NPs into serotonergic, DA, and motoneurons. The low expressors L1 and L3 were used in this study as they both exhibited vastly elevated neuronal differentiation compared to high expressors. Expression of serotonergic-, DA-, and motoneuron-specific markers, after differentiation induced by EB formation, was measured by real-time PCR. Since both L1 and L3 clones showed differences in the yield of neuronal differentiation compared with control cells (see Fig. 1), the expression level of each marker was normalized to Tuj1 (in addition to $\beta$-actin) to eliminate the bias resulting from overproduction of neurons by $h L m x 1 b$-expressing clones. E12.5 $d p c$ brain extract was used as a reference throughout these experiments. Clones L1 and L3 exhibited increased expression of serotonergic markers, 9and 3-fold for brain-specific serotonin producing enzyme Tph2, 7.7- and 2.5-fold for serotonin transporter (SERT), and 2.2-fold for serotonergic neuron-specific transcription factor Pet1 (only L1) (Fig. 2A). Of note, a slight increase in DA markers tyrosine hydroxylase (TH) and $L m x 1 a$ was also evidenced, whereas expression of Isl1, a marker of motoneuron differentiation, was significantly decreased (Fig. 2B). The enrichment in serotonergic neurons at day 17 of differentiation in $L m x 1 b$-overexpessing clones was confirmed by immunostaining against serotonin (Fig. 2C). Quantification of serotonin level by enzymatic immunoassay showed a 20 -fold increase in 5-HT content in both L1 and L3 clones compared with control cells (Fig. 2D). These results indicate that neural precursors overexpressing $h L m \times 1 b$ at a low level show increased propensity for differentiation into 5-HT neurons.

\section{Generation of an inducible expression vector and ES cells suitable for conditional gene expression in NPs and postmitotic neurons}

Since Lmx1b expression appeared detrimental to neural differentiation when overexpressed at high levels in $\mathrm{mES}$ cells, we generated an inducible expression system to drive conditional expression of hLmx1b in the NP population. To this aim, we made use of a hormone-dependant Cre-ER ${ }^{\mathrm{T} 2}$ recombinase and of an expression vector in which transgene transcription is blocked by 3 floxed transcription termination signals (Fig. 3A). This system displays 2 significant improvements with respect to our previously published system [29]: (1) the Cre-ER ${ }^{\mathrm{T} 2}$ recombinase is expressed from a lentiviral vector in which the Cre-ER ${ }^{\mathrm{T} 2}$ coding sequence is driven by the ubiquituously active truncated version of the EF1 $\alpha$ promoter [26]; (2) the expression vector contains $7 \mathrm{~kb}$ of genomic sequences that allow targeted integration into the ROSA26 locus and subsequent transgene expression under the ubiquitously active regulatory elements of ROSA26 [30]. A mES cell line expressing Cre-ER ${ }^{\mathrm{T} 2}$ was produced by infection with pR4SA-EFS-CreER ${ }^{\mathrm{T} 2}-\mathrm{W}$. This line, hereafter called WTC15, expresses CreER ${ }^{\mathrm{T} 2}$ at high level in ES cells and in their differentiated derivatives (data not shown). Next, an inducible vector called pIGTE2-R26-hPLAP that harbors $h P L A P$, the gene encoding hPLAP, was introduced by electroporation into WTC15 cells. Ten individual hygromycin-resistant clones were analyzed, of which 3 displayed homologous recombination into the ROSA26 locus (Fig. 3B). All 3 clones showed a 10- to 14 -fold increase in hPLAP activity upon treatment with $4^{\prime} \mathrm{OHT}(100 \mathrm{nM}, 48 \mathrm{~h})$ (Fig. 3C). One of them, hereafter called WTC-hPLAP-7, was selected for further analysis. Treatment with $4^{\prime} \mathrm{OHT}$ resulted in excision of the hygro-polyA cassette (Fig. 3D). Immunofluorescence staining showed hPLAP expression in most cells after treatment with $100 \mathrm{nM} 4^{\prime} \mathrm{OHT}$ for $48 \mathrm{~h}$ (Fig. 3E). Virtually, no hPLAP-positive cells could be detected in the untreated cell population, indicating that transgene expression was repressed completely in the absence of hormone.

WTC-hPLAP-7 cells were induced to differentiate into neuroepithelial colonies by means of coculture with MS5 stromal cells for 8 days, followed by amplification of the NP population by FGF2 for 3 days. To assess transgene induction in the neuroepithelial colonies, day 5 cultures were treated with $100 \mathrm{nM} 4^{\prime} \mathrm{OHT}$ for $48 \mathrm{~h}$. Expression of hPLAP was subsequently observed in $>95 \%$ of the neuroepithelial colonies (Fig. 4A, panels b, c). Day $11 \mathrm{NPs}$, derived from neuroepithelial colonies in which expression of the transgene was induced at day 5, expressed hPLAP in virtually all cells (Fig. 4A, panels e, f). Most neurons generated at day 17 also expressed it (Fig. 4A, panels h, i). Analysis of $h P L A P$ mRNA level by real-time PCR showed a 49-fold increase in day 11 NPs and a 9-fold increase in postmitotic neurons after induction with $4^{\prime} \mathrm{OHT}$ at the ES cell stage (day 0). When induction was performed at the neuroepithelial colony stage (day 5), a 51-fold increase in day 11 NPs and a 22-fold increase in postmitotic neurons were observed (Fig. 4B). Together, these results show that once induced, either in the undifferentiated state or during neural differentiation, hPLAP expression level is maintained throughout neuronal differentiation.

\section{Inducible expression of Lmx1b in ES-derived NPs stimulates neuronal production}

A mES cell line conditionally expressing $h L m x 1 b$ was engineered by electroporating pIGTE2-R26-hLmx1b plasmid into WTC15 mES cells. After selection, 9 hygromycin- 
resistant clone in 12 displayed targeted integration into the ROSA26 locus (Fig. 5A, B). Two homologous recombinant clones were tested, showing excision of the transcription termination cassette after $4^{\prime} \mathrm{OHT}$ treatment $(100 \mathrm{nM}, 48 \mathrm{~h})$ (Fig. 5C). Clone 6, hereafter called WTC-hLmx1b-6, was chosen for all subsequent experiments. Real-time PCR analysis of $h L m x 1 b$ expression in WTC-hLmx1b-6 showed a 55fold increase in mRNA level upon $4^{\prime} \mathrm{OHT}$ induction at the ES cell stage (day 0), and a 9- and 14-fold increase in postmitotic neurons after induction at day 0 and at the neuroepithelial colony stage (day 5), respectively (Fig. 5D). Of note, $h L m x 1 b$ expression levels in neurons produced from WTC-hLmx1b-6 ES cells after induction at day 5 were similar to expression levels measured in $h L m x 1 b$-stably expressing clones L1 and L2 (Fig. 5E). We also confirmed that the induction of $h L m x 1 b$ expression in WTC-hLmx1b-6 ES cell-derived NPs increased Map2ab expression at day 18 (Fig. 5F), as it was observed with hLmx1b-stable clones L1, L2, and L3 (see Fig. 1E, F).

\section{Inducible expression of $L m x 1 b$ cooperates with Sh, FGF4, and FGF8 to induce serotonergic differentiation}

We next asked whether the induction of $h L m x 1 b$ expression in NPs promotes expression of serotonergic markers. Expression of $h \operatorname{Lm} x 1 b$ was induced in the neuroepithelial colonies. After amplification in the presence of basic FGF, NPs were induced to differentiate into postmitotic neurons by mitogen withdrawal and the expression of serotonergic markers analyzed by real-time PCR. mRNA levels measured in the WTC-hLmx1b-6-derived neurons were normalized: first, to pan-neuronal Map2ab marker level to eliminate variations in the yield of neuronal differentiation; second, to mRNA levels measured in the WTC-hPLAP-7-derived neurons to eliminate nonspecific effects of $4^{\prime} \mathrm{OHT}$. We then observed a 1.4-, 1.6-, and 2.5-fold increase of Pet1, Tph2, and SERT mRNA levels, respectively (Fig. 6A).

Neuroepithelial colonies and amplifying NPs derived from both WTC-hPLAP-7 and WTC-hLmx1b-6 were exposed, either to Shh alone or to combinations of Shh and FGF4 (day 5-8) followed by Shh and FGF8 (day 8-12). This latter condition was described to promote serotonergic differentiation [3,6]. Expression of $h L m x 1 b$ and $h P L A P$ transgenes was induced by $4^{\prime} \mathrm{OHT}$ in the developing neuroepithelial colonies at day 5 . In the presence of Shh, induction of $h L m \times 1 b$ expression-when it was compared to induction of $h P L A P$-resulted in a 10-, 30-, and 55-fold increase in Pet1, Tph2, and SERT expression levels in postmitotic neurons at day 18, respectively (Fig. 6B). Treatment with Shh and FGF4, followed by Shh and FGF8, did not further increase expression of Tph2 (31-fold) and SERT (57fold), and moderately increased expression of Pet1 (16-fold) (Fig. 6C). Treatment with Shh combined with induced expression of $h L m x 1 b$ also increased expression of DA markers, En (2.8-fold), TH (18.5-fold), and Nurr1 (6.6-fold), when compared with expression levels in Shh-treated control cells (Fig. 6D). Further, addition of FGF4 and FGF8 to the differentiation cocktail reduced expression of TH and Nurr1 by
A
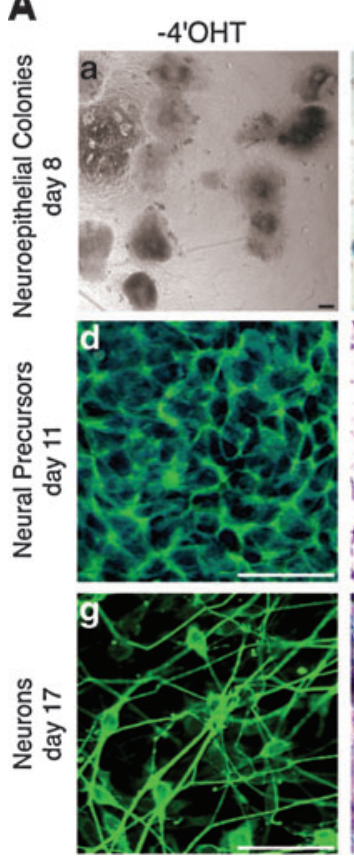
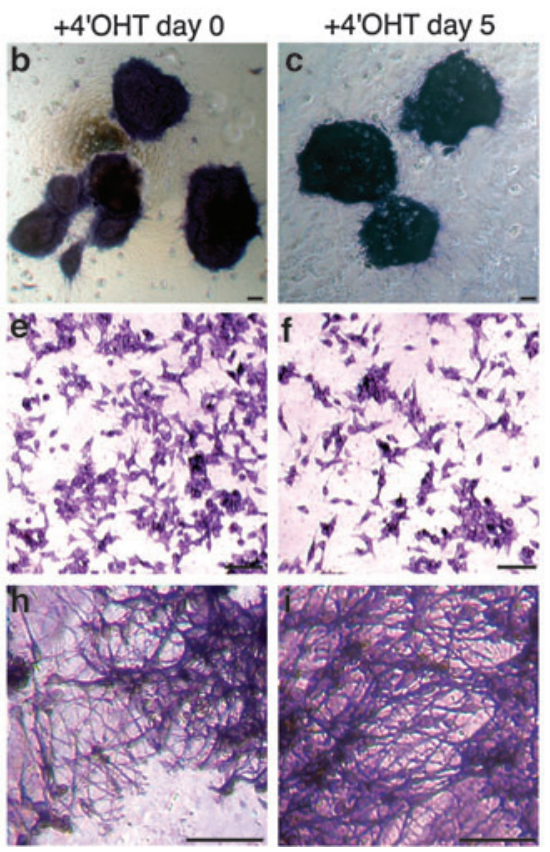

B

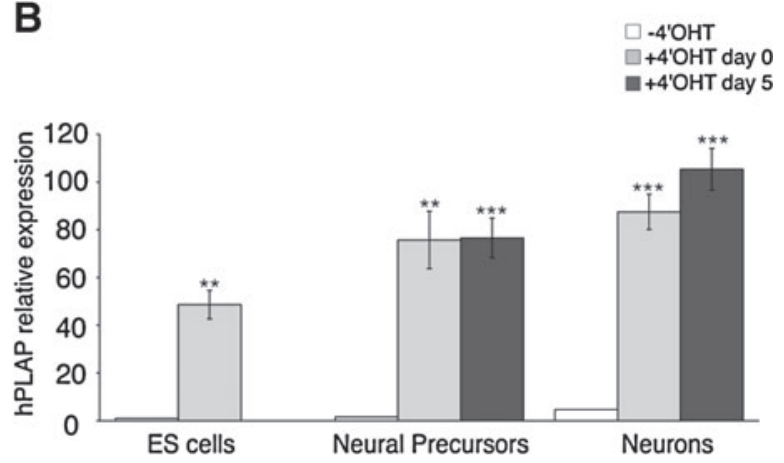

FIG. 4. Conditional expression of hAP in neuroepithelial colonies, NPs, and postmitotic neurons. (A) Immunohistochemical analysis of hAP expression in neuroepithelial colonies at day $8(\mathbf{b}, \mathbf{c})$, in NPs at day $11(\mathbf{e}, \mathbf{f})$, and in neurons at day 18 , following induction with 4'OHT (100 nM, $48 \mathrm{~h})$, either in undifferentiated $\mathrm{mES}$ cells $\mathbf{( b}, \mathbf{e}, \mathbf{h})$ or in neuroepithelial colonies at day 5 (c, f, i). Left panels show unstained neuroepithelial colonies (a), NPs after immunolabeling for PSA-NCAM (green) (d), and neurons after immunolabeling for Tuj1 (green) (g). DNA is counterstained with DAPI. Scale bar: $100 \mu \mathrm{m}$. (B) Real-time PCR analysis of $h P L A P$ expression in ES cells after induction at day 0 , in day 11 NPs after induction both at day 0 and at day 5 , and in day 17 neurons after induction both at day 0 and at day 5 . Expression levels are normalized to the level measured in mES cells before induction. $\left({ }^{* *} P<0.01 ;{ }^{* * *} P<0.001\right)$. 
2-fold in comparison with Shh alone (Fig. 6E), which is likely to reflect the capacity of FGF4 to inhibit DA differentiation [11].

Taken together, these results show that enforced expression of Lmx1b, combined with Shh, robustly stimulates expression of serotonergic markers in the differentiating NPs derived from mES cells.

\section{Discussion}

The focus of this study was to demonstrate the role of Lmx1b in promoting differentiation of mES cell-derived NPs into serotonergic neurons. Lmx1b is essential to the development of the entire serotonergic system [17-19], as well as to the maintenance of the DA neurotransmitter phenotype in the mouse [21]. We thus asked if overexpression of Lmx1b in mES cells is sufficient to specify serotonergic and DA phenotypes.

Forced expression of a transgene that drives differentiation often results in inability to form undifferentiated mES colonies and consequent recovery only of low expressing or deviant cells. We successfully generated mES cell lines that express hLmx1b ectopically, but only the lines expressing it at low level retained the capacity to differentiate into neural precursors harboring the growth characteristics of control cells. In contrast, mES cells expressing Lmx1b at high levels exhibited reduced capacity to form NPs, and those progenitors to differentiate into postmitotic neurons. Failure to differentiate could result either from the detrimental effect of Lmx1b when overexpressed at elevated levels, or from the selection of mutant mES cells that resisted to the differentiation-promoting effect of Lmx1b. To overcome this difficulty,
A

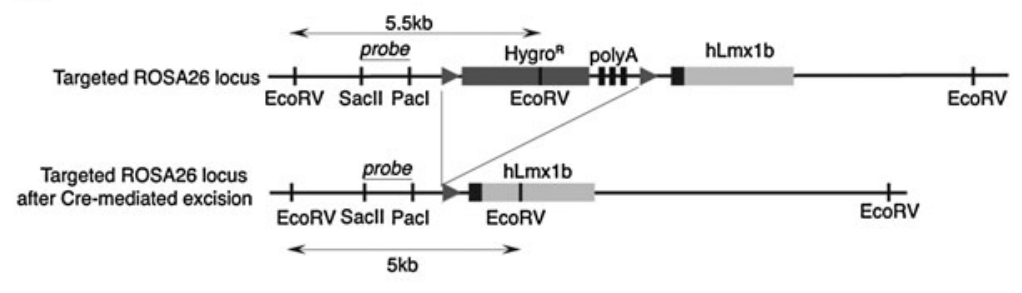

B

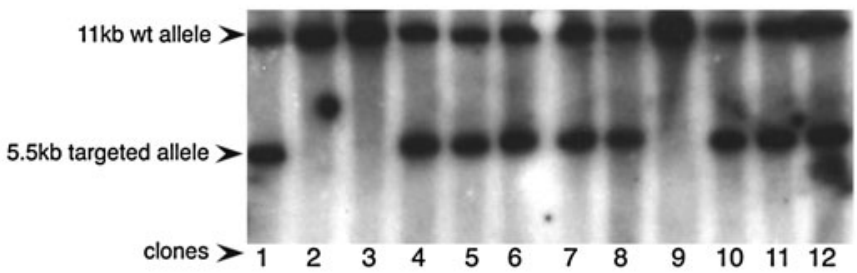

C

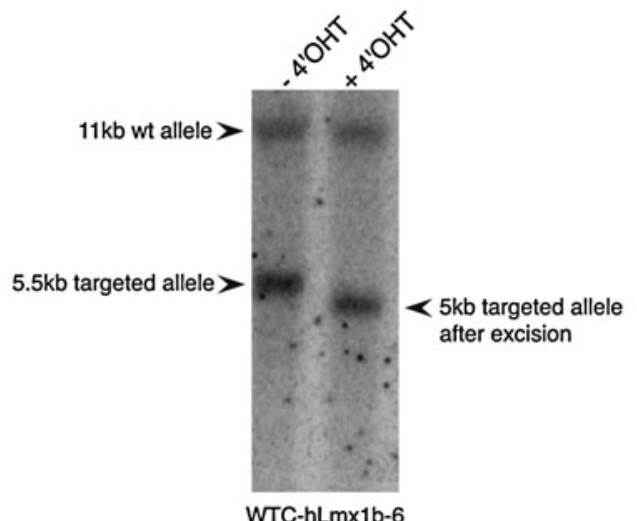

D

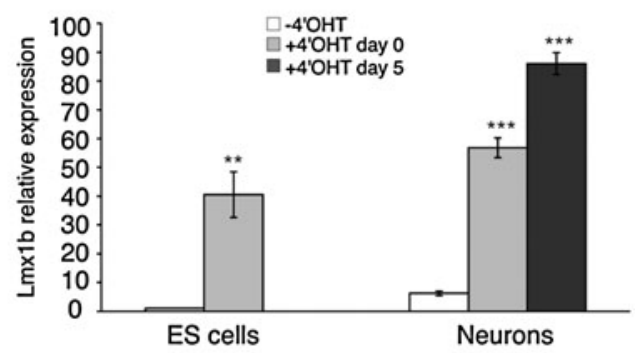

E

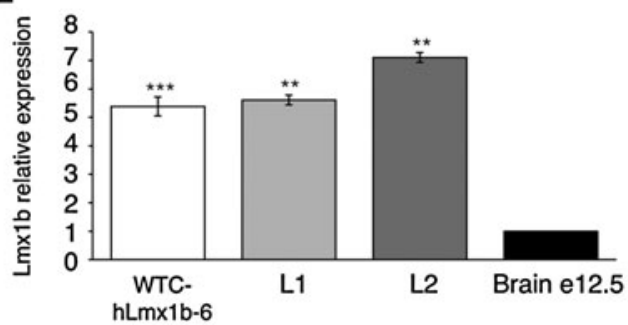

$\mathbf{F}$

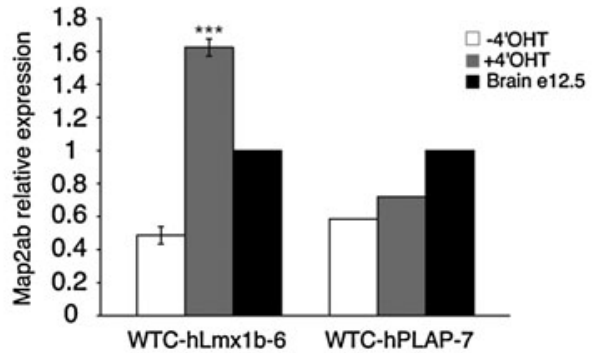

FIG. 5. Conditional expression of $h L m x 1 b$ in neurons. (A) Schematic representation of the ROSA26 locus after targeted integration of $p I G T E 2-R 26-h L m x 1 b$ plasmid, before and after Cre-mediated excision of the hygro-polyA cassette. The position of the SacII-PacI probe used for Southern blot analysis is indicated. $H_{g r r o}{ }^{R}$, gene conferring resistance to hygromycin B; PolyA, transcription termination and polyadenylation signals. (B) Southern blot analysis of the ROSA26 locus after digestion with EcoRV and hybridization with a radioactive probe. (C) Southern blot analysis of the ROSA26 locus in WTC15-R26-hLmx1b-6 clone after digestion with $E c o R V$, before and after treatment with $4^{\prime} \mathrm{OHT}(100 \mathrm{nM}, 48 \mathrm{~h})$. (D) Real-time PCR analysis of $h L m x 1 b$ expression in neurons derived from WTC-Lmx1b-6 clone after induction with 4'OHT either at day 0 (undifferentiated ES cells) or at day 5 (neuroepithelial colonies). (E) Real-time PCR analysis of $h L m x 1 b$ expression in neurons derived from WTC-Lmx1b-6 clone (after induction with $4^{\prime} \mathrm{OHT}$ at day 5) and in neurons derived from hLmx1b-stably expressing clones L1 and L2. (F) Real-time PCR analysis of Map2ab expression in neurons derived from WTC-hPLAP-7 and WTC-hLmx1b-6 clone, after induction with $4^{\prime} \mathrm{OHT}$ at day 5. (E, F) Expression levels are normalized to the level measured in e12.5 total brain. (D, E, F) ${ }^{* * P}<0.01 ;{ }^{* * *} P<0.001$. 
A

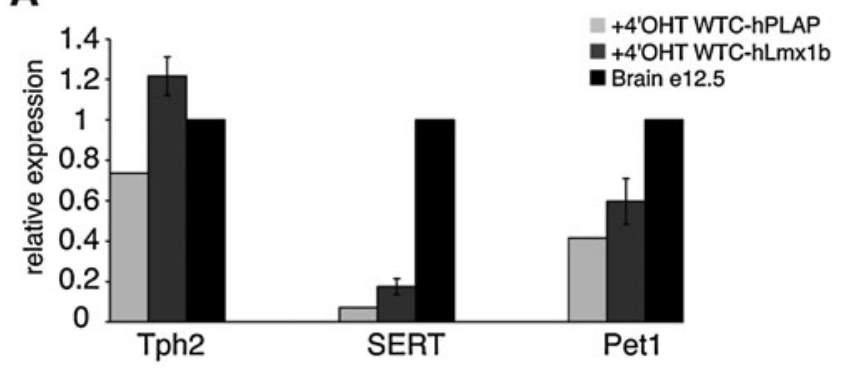

C

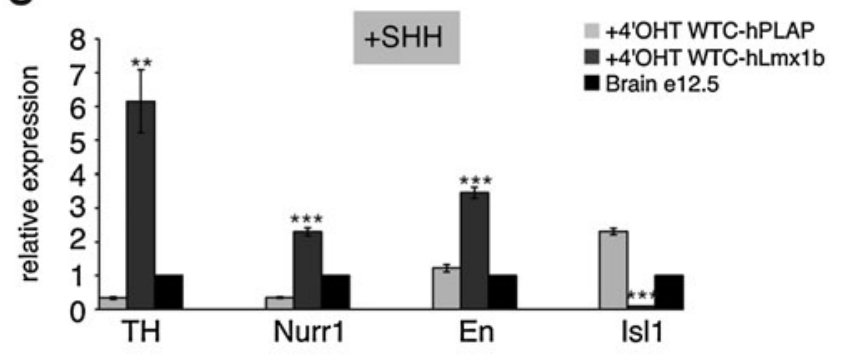

B

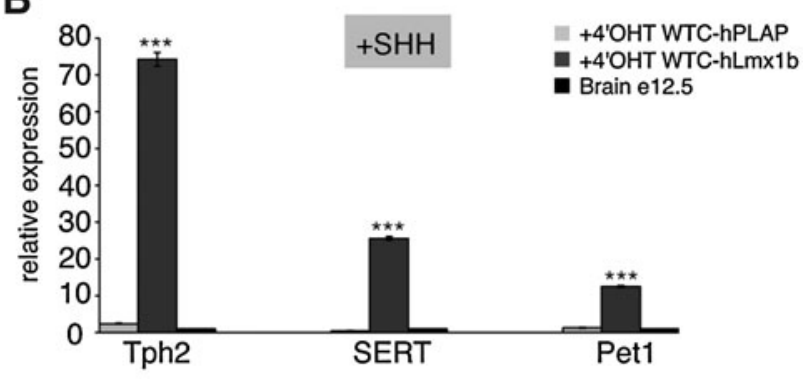

D

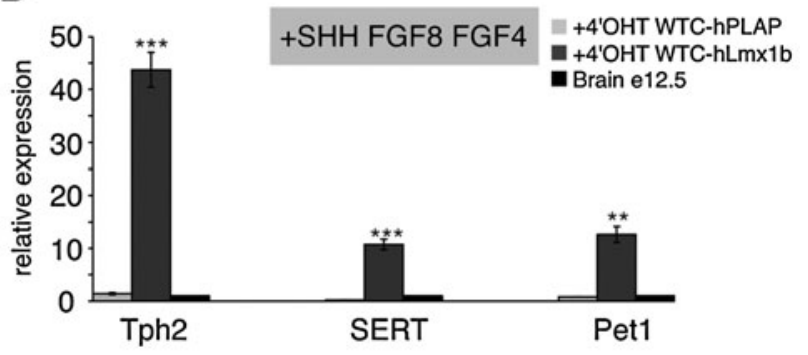

E

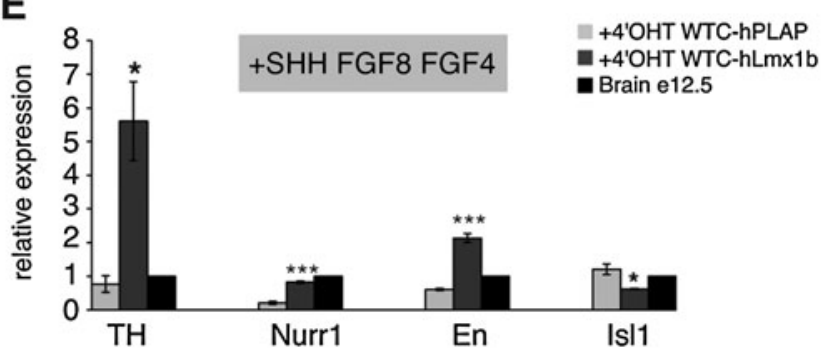

FIG. 6. Inducible expression of hLmx1b in ES-derived NPs increases expression of serotonergic markers. (A-C) Real-time PCR analysis of Petl, Tph2, and SERT mRNA levels in day 18 neurons derived from WTC-HLmx1b-6 clone after induction with $4^{\prime} \mathrm{OHT}$ at day 5 (neuroepithelial colonies), in the absence of dorsoventralizing factors (A) or in the presence of sonic hedgehog (Shh) (B) or in the presence of Shh, fibroblast growth factor 4 (FGF4), and FGF8 (C). (D, E) Real-time PCR analysis of En, TH, and Nurrl mRNA levels in day 18 neurons derived from WTC-HLmx1b-6 clone after induction with $4^{\prime} \mathrm{OHT}$ at day 5 (neuroepithelial colonies), either in the absence of dorsoventralizing factors (D) or in the presence of Shh, FGF4, and FGF8 (E). (A-E) Expression levels are normalized to the level measured in e12.5 total brain. (A-E) ${ }^{*} P<0.05 ;{ }^{* *} P<0.01 ;{ }^{* * *} P<0.001$.

we have engineered an inducible gene expression system that makes possible to overexpress differentiation-promoting genes in mES cell-derived NPs and to maintain their expression in differentiating neurons. Activation of $h L m \times 1 b$ in mES cell-derived NPs and its subsequent expression in postmitotic neurons, as revealed by the hPLAP reporter gene, reflect the expression pattern of $L m x 1 b$ in the mouse, starting in NPs of the hindbrain and being maintained in mature 5HT neurons [17].

In both stably induced and $4^{\prime} \mathrm{OHT}$-induced Lmx1b expressing mES cells, we observed that Lmx1b increases expression Tph2, SERT, and Pet1, the landmarks of serotonergic neurotransmitter phenotype. The effect of Lmx1b was observed using 2 different differentiation protocols, the first one based on coculture of ES cells with a stromal feeder cell line [3] and the second one based on EB formation [5], both of them including selection and amplification of nestin ${ }^{+}$NPs. These results indicate that $L m x 1 b$ expression is rate limiting for specifying the 5-HT phenotype, in accordance with the genetic data in the mouse [17-19]. The inductive effect of Lmx1b on serotonergic differentiation is strongly enhanced when NPs are treated with the floor plate signal Shh. This result can be explained by the capacity of Shh to activate expression of ancillary factors acting in concert with Lmx1b to promote serotonergic differentiation. Indeed, the specification of serotonergic neurons requires a Shh-regulated cascade of transcription factors to generate 5-HT neurons in vivo. Shh-activated homeodomain proteins $\mathrm{Nkx2.2}$ and Nkx6.1 cooperate to induce closely related zinc-finger transcription factors GATA2 and GATA3. Preceding the induction of 5-HT neurons, GATA2 activates both Lmx1b and Pet1 consistent with the timing of their expression in vivo $[17,18,20]$. Ultimately, Pet1 contributes to serotonergic differentiation since mice lacking Pet1 shows a loss of $70 \%-80 \%$ of 5-HT neurons in the CNS [16], whereas $L m x 1 b$ knockout mice lack all central 5-HT neurons [14,16,17]. In addition, both $L m x 1 b$ and Pet1 have been shown to be necessary and sufficient to specify 5-HT transmitter phenotype when overexpressed in the chick ventral spinal cord [18]. Whether Lmx $1 b$ and Pet1 act strictly in parallel to specify 5-HT neurotransmitter phenotype [18], or whether Pet1 is also a target gene of Lmx1b [17] is still unclear. During development, 
expression of $L m x 1 b$ precedes that of Pet1. Moreover, Pet1 expression is lost in $L m x 1 b$ knockout mice, raising the possibility that the maintenance of Pet1 expression is dependent on $\operatorname{Lmx} 1 b[17,18]$. Whether this reflects a loss of $5-\mathrm{HT}$ neurons or gene regulation by $L m \times 1 b$ remained unclear. Interestingly, the study of conditional deletion of $L m x 1 b$ at e12.5 showed that initiation of Pet1 expression is independent from Lmx1b [18], but maintenance of its expression requires Lmx1b [19]. Therefore, our observation that Pet1 expression is moderately increased in neurons overexpressing $h L m x 1 b$ suggests that Pet1 is responsive to Lmx1b induction, and that Lmx1b reinforces the transcriptional activity of Pet1 $[17,18]$.

The development of 5-HT neurons depends critically on FGF8 generated at the midbrain-hindbrain boundary and on FGF4 produced by the primitive streak. In vivo, FGF4 inhibits the development of midbrain DA neurons and promotes the development of 5-HT neurons [11]. In mES cellderived NPs treated with $4^{\prime} \mathrm{OHT}$ to activate Lmx1b expression, addition of Shh, FGF4, and FGF8 has no effect on the yield of serotonergic differentiation compared to a sister culture treated with Shh alone. Thus, when Lmx1b is overexpressed, FGF8 and FGF4 become dispensable for serotonergic differentiation. This finding suggests that activation of Lmx1b expression is the main consequence of FGF8 and FGF4 induction in the developing NPs acquiring a 5-HT phenotype.

Our experiments show that overexpression of Lmx1b, either alone or in combination with Shh, has little or no effect on the yield of DA neuron differentiation. This is in accordance with a previous report [35] showing that transduction of mouse and hES cells with $L m x 1 b$ does not induce maturation to the midbrain DA neuron phenotype unless Nurr1 is cotransduced in the same cell. Noteworthy, addition of FGF8 and FGF4 slightly reduced expression of midbrain DA neuron markers in accordance with the function of FGF4 in vivo [11].

To summarize, our results underline the need for proper extrinsic signals combined with intrinsic clues when engineering and manipulating ES cells for differentiation purposes. The vectors and cell lines described might be of great value for studying the gene function in serotonergic neuron development and disease pathology and in trying to understand how drugs that affect the serotonergic system alter neurotransmitter release.

\section{Acknowledgments}

This work was supported by research grants from the European Union 6th Framework Program (FunGenES, contract No. LSHG-CT-2003-503494), INSERM AVENIR program, Région Rhône-Alpes (Cluster Handicap, Vieillissement, Neuroscience), Fondation Bettencourt-Schueller, European Science Fundation, FuncDyn Program, and Fondation CERA.

\section{Author Disclosure Statement}

No competing financial interests exist.

\section{References}

1. Smith AG. (2001). Embryo-derived stem cells: of mice and men. Annu Rev Cell Dev Biol 17:435-462.

2. Lee SH, N Lumelsky, L Studer, JM Auerbach and RD McKay. (2000). Efficient generation of midbrain and hind- brain neurons from mouse embryonic stem cells. Nat Biotechnol 18:675-679.

3. Barberi T, P Klivenyi, NY Calingasan, H Lee, H Kawamata, K Loonam, AL Perrier, J Bruses, ME Rubio, N Topf, V Tabar, NL Harrison, MF Beal, MA Moore and L Studer. (2003). Neural subtype specification of fertilization and nuclear transfer embryonic stem cells and application in parkinsonian mice. Nat Biotechnol 21:1200-1207.

4. Salli U, AP Reddy, N Salli, NZ Lu, HC Kuo, FK Pau, DP Wolf and CL Bethea. (2004). Serotonin neurons derived from rhesus monkey embryonic stem cells: similarities to CNS serotonin neurons. Exp Neurol 188:351-364.

5. Alenina N, S Bashammakh and M Bader. (2006). Specification and differentiation of serotonergic neurons. Stem Cell Rev 2:5-10.

6. Kumar M, SK Kaushalya, P Gressens, S Maiti and S Mani. (2009). Optimized derivation and functional characterization of 5-HT neurons from human embryonic stem cells. Stem Cells Dev 18:615-627.

7. Tokuyama Y, SL Ingram, JS Woodward and CL Bethea. (2010). Functional characterization of rhesus embryonic stem cell-derived serotonin neurons. Exp Biol Med (Maywood) 235:649-657.

8. Millet S, K Campbell, DJ Epstein, K Losos, E Harris and AL Joyner. (1999). A role for Gbx2 in repression of Otx2 and positioning the mid/hindbrain organizer. Nature 401:161-164.

9. Joyner AL, A Liu and S Millet. (2000). Otx2, Gbx2 and Fgf8 interact to position and maintain a mid-hindbrain organizer. Curr Opin Cell Biol 12:736-741.

10. Brodski C, DM Weisenhorn, M Signore, I Sillaber, M Oesterheld, V Broccoli, D Acampora, A Simeone and W Wurst. (2003). Location and size of dopaminergic and serotonergic cell populations are controlled by the position of the midbrain-hindbrain organizer. J Neurosci 23:4199-4207.

11. Ye W, K Shimamura, JL Rubenstein, MA Hynes and A Rosenthal. (1998). FGF and Shh signals control dopaminergic and serotonergic cell fate in the anterior neural plate. Cell 93:755-766.

12. Ye W, M Bouchard, D Stone, X Liu, F Vella, J Lee, H Nakamura, SL Ang, M Busslinger and A Rosenthal. (2001). Distinct regulators control the expression of the midhindbrain organizer signal FGF8. Nat Neurosci 4:1175-1181.

13. Pattyn A, N Simplicio, JH van Doorninck, C Goridis, F Guillemot and JF Brunet. (2004). Ascl1/Mash1 is required for the development of central serotonergic neurons. Nat Neurosci 7:589-595.

14. Hendricks T, N Francis, D Fyodorov and ES Deneris. (1999). The ETS domain factor Pet-1 is an early and precise marker of central serotonin neurons and interacts with a conserved element in serotonergic genes. J Neurosci 19:10348-10356.

15. van Doorninck JH, J van Der Wees, A Karis, E Goedknegt, JD Engel, M Coesmans, M Rutteman, F Grosveld and CI De Zeeuw. (1999). GATA-3 is involved in the development of serotonergic neurons in the caudal raphe nuclei. J Neurosci 19:RC12.

16. Hendricks TJ, DV Fyodorov, LJ Wegman, NB Lelutiu, EA Pehek, B Yamamoto, J Silver, EJ Weeber, JD Sweatt and ES Deneris. (2003). Pet-1 ETS gene plays a critical role in 5-HT neuron development and is required for normal anxiety-like and aggressive behavior. Neuron 37:233-247.

17. Ding YQ, U Marklund, W Yuan, J Yin, L Wegman, J Ericson, E Deneris, RL Johnson and ZF Chen. (2003). Lmx1b is essential for the development of serotonergic neurons. Nat Neurosci 6:933-938. 
18. Cheng L, CL Chen, P Luo, M Tan, M Qiu, R Johnson and Q Ma. (2003). Lmx1b, Pet-1, and Nkx2.2 coordinately specify serotonergic neurotransmitter phenotype. J Neurosci 23:9961-9967.

19. Zhao ZQ, M Scott, S Chiechio, JS Wang, KJ Renner, RWt Gereau, RL Johnson, ES Deneris and ZF Chen. (2006). $\mathrm{Lm} \times 1 \mathrm{~b}$ is required for maintenance of central serotonergic neurons and mice lacking central serotonergic system exhibit normal locomotor activity. J Neurosci 26:12781-12788.

20. Craven SE, KC Lim, W Ye, JD Engel, F de Sauvage and A Rosenthal. (2004). Gata2 specifies serotonergic neurons downstream of sonic hedgehog. Development 131:1165-1173.

21. Smidt MP, CH Asbreuk, JJ Cox, H Chen, RL Johnson and JP Burbach. (2000). A second independent pathway for development of mesencephalic dopaminergic neurons requires Lmx1b. Nat Neurosci 3:337-341.

22. Kim JH, JM Auerbach, JA Rodriguez-Gomez, I Velasco, D Gavin, N Lumelsky, SH Lee, J Nguyen, R Sanchez-Pernaute, $\mathrm{K}$ Bankiewicz and R McKay. (2002). Dopamine neurons derived from embryonic stem cells function in an animal model of Parkinson's disease. Nature 418:50-56.

23. Reubinoff BE, MF Pera, CY Fong, A Trounson and A Bongso. (2000). Embryonic stem cell lines from human blastocysts: somatic differentiation in vitro. Nat Biotechnol 18:399-404.

24. Ben-Hur T, M Idelson, $H$ Khaner, M Pera, E Reinhartz, A Itzik and BE Reubinoff. (2004). Transplantation of human embryonic stem cell-derived neural progenitors improves behavioral deficit in Parkinsonian rats. Stem Cells 22:1246-1255.

25. Feil R, J Wagner, D Metzger and P Chambon. (1997). Regulation of Cre recombinase activity by mutated estrogen receptor ligand-binding domains. Biochem Biophys Res Commun 237:752-757.

26. Mangeot PE, D Negre, B Dubois, AJ Winter, P Leissner, M Mehtali, D Kaiserlian, FL Cosset and JL Darlix. (2000). Development of minimal lentivirus vectors derived from simian immunodeficiency virus (SIVmac251) and their use for gene transfer into human dendritic cells. J Virol 74:8307-8315.

27. Wianny F, A Bernat, G Marcy, C Huissoud, S Markossian, V Leviel, H Kennedy, P Savatier and C Dehay. (2008). Derivation and cloning of a novel Rhesus ES cell line stably expressing tau-GFP. Stem Cells 26:1444-1453.

28. Suter DM, L Cartier, E Bettiol, D Tirefort, ME Jaconi, M Dubois-Dauphin and KH Krause. (2006). Rapid generation of stable transgenic embryonic stem cell lines using modular lentivectors. Stem Cells 24:615-623.

29. Vallier L, J Mancip, S Markossian, A Lukaszewicz, C Dehay, D Metzger, P Chambon, J Samarut and P Savatier. (2001). An efficient system for conditional gene expression in embryonic stem cells and in their in vitro and in vivo differentiated derivatives. Proc Natl Acad Sci U S A 98:2467-2472.
30. Srinivas $\mathrm{S}, \mathrm{T}$ Watanabe, CS Lin, CM William, Y Tanabe, TM Jessell and F Costantini. (2001). Cre reporter strains produced by targeted insertion of EYFP and ECFP into the ROSA26 locus. BMC Dev Biol 1:4.

31. Wiles MV and BM Johansson. (1999). Embryonic stem cell development in a chemically defined medium. Exp Cell Res 247:241-248.

32. Tropepe V, S Hitoshi, C Sirard, TW Mak, J Rossant and D van der Kooy. (2001). Direct neural fate specification from embryonic stem cells: a primitive mammalian neural stem cell stage acquired through a default mechanism. Neuron 30:65-78.

33. Negre D, PE Mangeot, G Duisit, $S$ Blanchard, PO Vidalain, $P$ Leissner, AJ Winter, C Rabourdin-Combe, M Mehtali, P Moullier, JL Darlix and FL Cosset. (2000). Characterization of novel safe lentiviral vectors derived from simian immunodeficiency virus (SIVmac251) that efficiently transduce mature human dendritic cells. Gene Ther 7:1613-1623.

34. Dull T, R Zufferey, M Kelly, RJ Mandel, M Nguyen, D Trono and L Naldini. (1998). A third-generation lentivirus vector with a conditional packaging system. J Virol 72:8463-8471.

35. Martinat C, JJ Bacci, T Leete, J Kim, WB Vanti, AH Newman, JH Cha, U Gether, H Wang and A Abeliovich. (2006). Cooperative transcription activation by Nurr1 and Pitx3 induces embryonic stem cell maturation to the midbrain dopamine neuron phenotype. Proc Natl Acad Sci U S A 103:2874-2879.

Address correspondence to: Dr. Pierre Savatier

INSERM U846

18 Avenue Doyen Lépine 69500 Bron

France

E-mail: pierre.savatier@inserm.fr

Dr. Agnieszka Bernat INSERM U846

18 Avenue Doyen Lépine 69500 Bron

France

E-mail: agnieszka.bernat@inserm.fr

Received for publication June 8, 2010

Accepted after revision July 22, 2010

Prepublished on Liebert Instant Online July 22, 2010 
